\title{
АНАЛІЗ НАПРУЖЕНОГО СТАНУ ПОРОЖНИСТИХ ДЕТАЛЕЙ В ПРОЦЕСІ ЗВОРОТНО-РАДІАЛЬНОГО ВИДАВЛЮВАННЯ
}

Розвиток машинобудування в сучасних умовах вимагає розробки нових, більш досконалих технологій одержання високоякісних заготовок з мінімальною собівартістю.

Основною вимогою машинобудування є максимальне наближення розмірів і конфігурації заготовок до чистових деталей, підвищення їх механічних властивостей і зниження собівартості. Чим ближче розміри заготовок до готових деталей і чим вище їх механічні властивості, тим легше їх вага і менше трудомісткість подальшої обробки різанням. Виготовляти порожнисті складнопрофільовані деталі можливо як традиційно використовуваними способами, що включають в себе поздовжнє і поперечне видавлювання, так і способами видавлювання з рухомим формуючим інструментом [1-3].

Видавлювання за схемами з рухомим формуючим інструментом дозволяє отримувати порожнисті деталі досить складної форми. Для розвитку процесів штампування ефективне застосування способів комбінованого видавлювання вісесиметричних деталей, що може дозволити розширити їх номенклатуру шляхом ускладнення їх конфігурації, знизити кількість технологічних переходів і зменшити навантаження на інструмент [3-6].

Обробка тиском металів у холодному стані має ряд очевидних переваг як перед обробкою різанням, так і перед гарячими процесами обробки металів тиском. По-перше, холодна обробка тиском забезпечує виготовлення поковок, близьких по розмірах до готової деталі, що значно скорочує, а в деяких випадках і виключає подальшу обробку, а також забезпечує високий коефіцієнт використання металу. По-друге, значно підвищуються механічні властивості деталі, так як в структурі металу відсутні перерізані волокна, а так само наявність зміцнення може виключити подальшу зміцнюючу термообробку та забезпечити застосування менш міцних, але більш пластичних конструкційних матеріалів. Також, холодне деформування значно підвищує продуктивність праці [7].

Технологічні процеси видавлювання відрізняються різноманітністю можливостей, piзноманіттям і високою ефективністю в порівнянні з іншими процесами формоутворення деталей. Пошук нових схем деформування, спрямованих на підвищення якості деталей, складності їх форми, стійкості інструменту доцільно здійснити в області нових схем деформування. До таких способів можна віднести поперечне і комбіноване зворотно-радіальне видавлювання, видавлювання рідиною високого тиску і локальним навантаженням, видавлювання 3 протитиском $[8,9]$.

Складнопрофільовані порожнисті вироби типу стакан широко поширені в промисловості, традиційно виготовляють холодним поздовжнім (зворотним або прямим) видавлюванням.

Метою роботи є дослідження напружено-деформованого стану, а також моделювання силового режиму процесу зворотно-радіального видавлювання.

На рис. 1 розглядається схема процесу зворотно-радіального видавлювання (а - видавлювання першого потовщення стінки стакану, б - переміщення матриці вниз в нове положення для видавлювання другого потовщення в стінці стакану, в - видавлювання другого потовщення стінки стакану) і отримана деталь (2).

Обрані наступні параметри для моделювання за допомогою програми на основі методу скінченних елементів QForm 2D/3D процесу зворотно-радіального видавлювання:

- механічні властивості - матеріал заготовки АМцМ: крива істинних напружень описується рівнянням $\sigma_{\mathrm{s}}(\varepsilon)=188,4 \cdot \varepsilon^{0,15}$, межа плину $\sigma_{0.2}=105 \mathrm{MПа,} \mathrm{модуль} \mathrm{Юнга}$ $E=75000$ МПа, коефіцієнт Пуассона $v=0,3$ і коефіцієнт тертя між матеріалом заготовки і інструментом $\mu=0,08$ (закон Зібеля). 
- геометричні параметри процесу: $R_{0}$ - радіус заготовки $\left(R_{0}=22,5 \mathrm{Mм}\right), R$ - радіус пуансона $\left(R=17\right.$ мм), $R_{1}$ - радіус фланця $\left(R=26,3\right.$ мм), $L_{l}-$ висота приймальної порожнини для фланця, що видавлюється $\left(L_{l}=15 \mathrm{Mм}\right), L-$ висота заготовки $(L=75 \mathrm{Mm}), r-$ радіус заокруглення кромок інструменту $(r=2,0$ мм).

- силові параметри процесу: $P$ - сила видавлювання, $V$ - швидкість пуансона, $V_{l}$ - швидкість матриці.

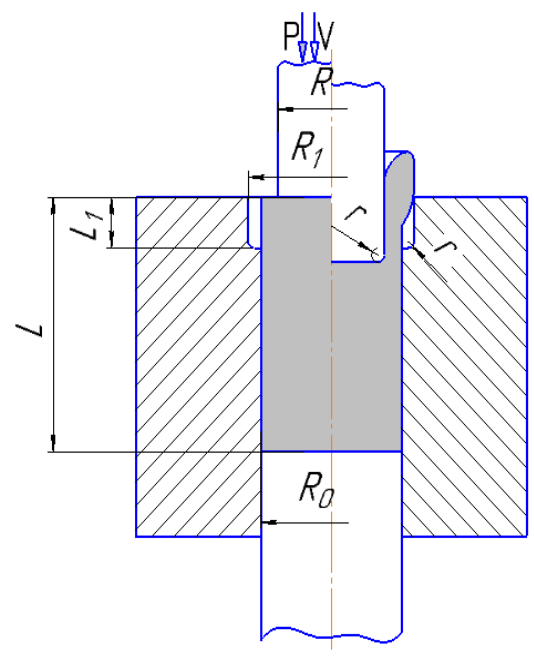

a

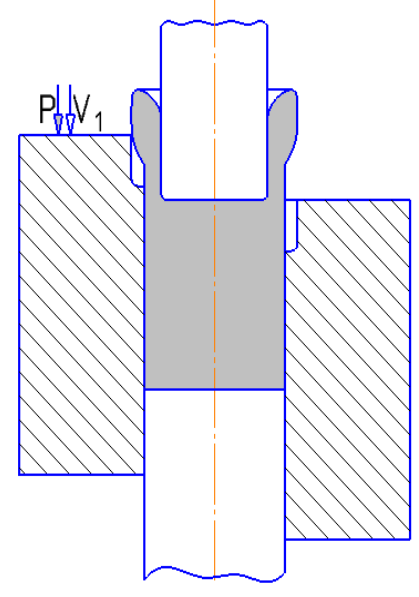

б

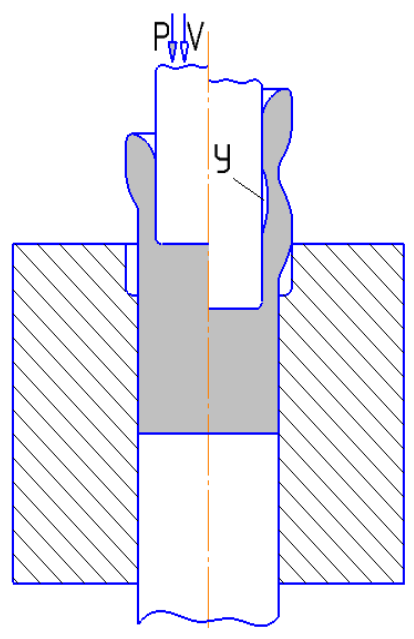

B

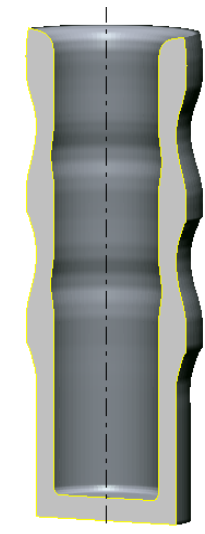

$\Gamma$

Рис. 1. Схема процесу зворотно-радіального видавлювання (а - видавлювання першого потовщення стінки стакану, б-переміщення матриці вниз в нове положення для видавлювання другого потовщення в стінці стакану, в - видавлювання другого потовщення стінки стакану) і отримана деталь (2)

На рис. 2 представлено результати моделювання процесу зворотно-радіального видавлювання такі, як розподіл інтенсивності деформацій $\varepsilon_{\mathrm{i}}(a)$ і напружень $\sigma_{\mathrm{i}}$, МПа (б) за ходом деформування.

Осередок деформації зосереджений під пуансоном на певну глибину і в стінці одержуваного стакану, максимальне значення інтенсивності деформацій $\varepsilon_{\mathrm{i}}=6,5$ спостерігаються у зоні перехідної кромки пуансона (в області калібруючого пояска пуансона), а розташування зон з максимальним значенням інтенсивності напружень в $\sigma_{\mathrm{i}}=190 \mathrm{MПа} \mathrm{майже} \mathrm{збігається}$ з розміщенням осередку деформації в деформованому об'ємі.

На рис. 1 та 2 можна спостерігати утягнення (незаповнення об'єму) на внутрішній поверхні порожнини (на рис. 1 утягнення позначено буквою У). Утягнення з'являються на початку утворення чергового потовщення на зовнішній поверхні стакану в процесі зворотнорадіального видавлювання через відхід металу заготовки, що деформується, від поверхні пуансона при радіальній течії.

На рис. 3 зображено графік залежності сили процесу від ходу пуансона. На ньому видно, що по ходу процесу сила зростає. Чітко виділені три зони - це зони формування потовщень. Від 0 до 20 мм здійснюється формування першого потовщення (зусилля зростає від $\mathrm{P}=0$ кН до $\mathrm{P}=500$ кН), потім відбувається спад до $\mathrm{P}=0$ кН через те, що пуансон зупиняється, а матриця при цьому переміщується вниз на рівень формування наступного потовщення. Потім знову сила зростає від $\mathrm{P}=0$ кН до $\mathrm{P}=500$ кН (хід від 20 до $40 \mathrm{мм}$ ) через формування другого потовщення. Після цього знову пуансон зупиняється $(\mathrm{P}=0 \mathrm{\kappa H})$, а матриця переміщується в наступне положення (для формування третього потовщення). В останнє сила зростає від $\mathrm{P}=0$ кН до $\mathrm{P}=570$ кН при формуванні третього потовщення та кінцевих розмірів деталі. Сила $\mathrm{P}=570$ кН перевищує силу $\mathrm{P}=500$ кН, яка спостерігалась на двох попередніх етапах через те що в кінці видавлювання відбувається зменшення осередку деформації, який був сформований ще на першому етапі. 


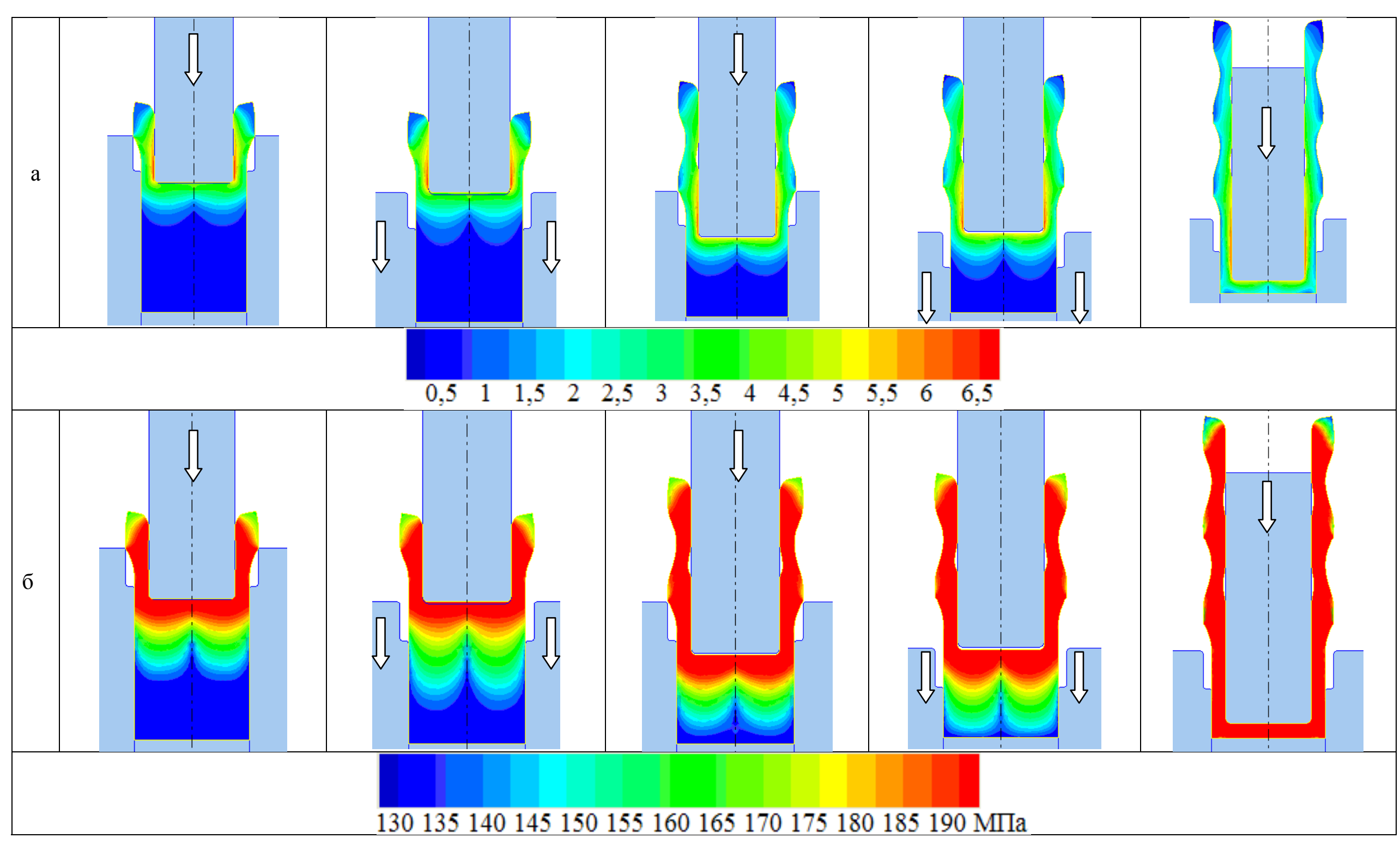

Рис. 2. Розподіл інтенсивності деформацій $\varepsilon_{\mathrm{i}}(a)$, розподіл інтенсивності напружень $\sigma_{\mathrm{i}}$, МПа (б) за ходом деформування при зворотно-радіальному видавлюванні 


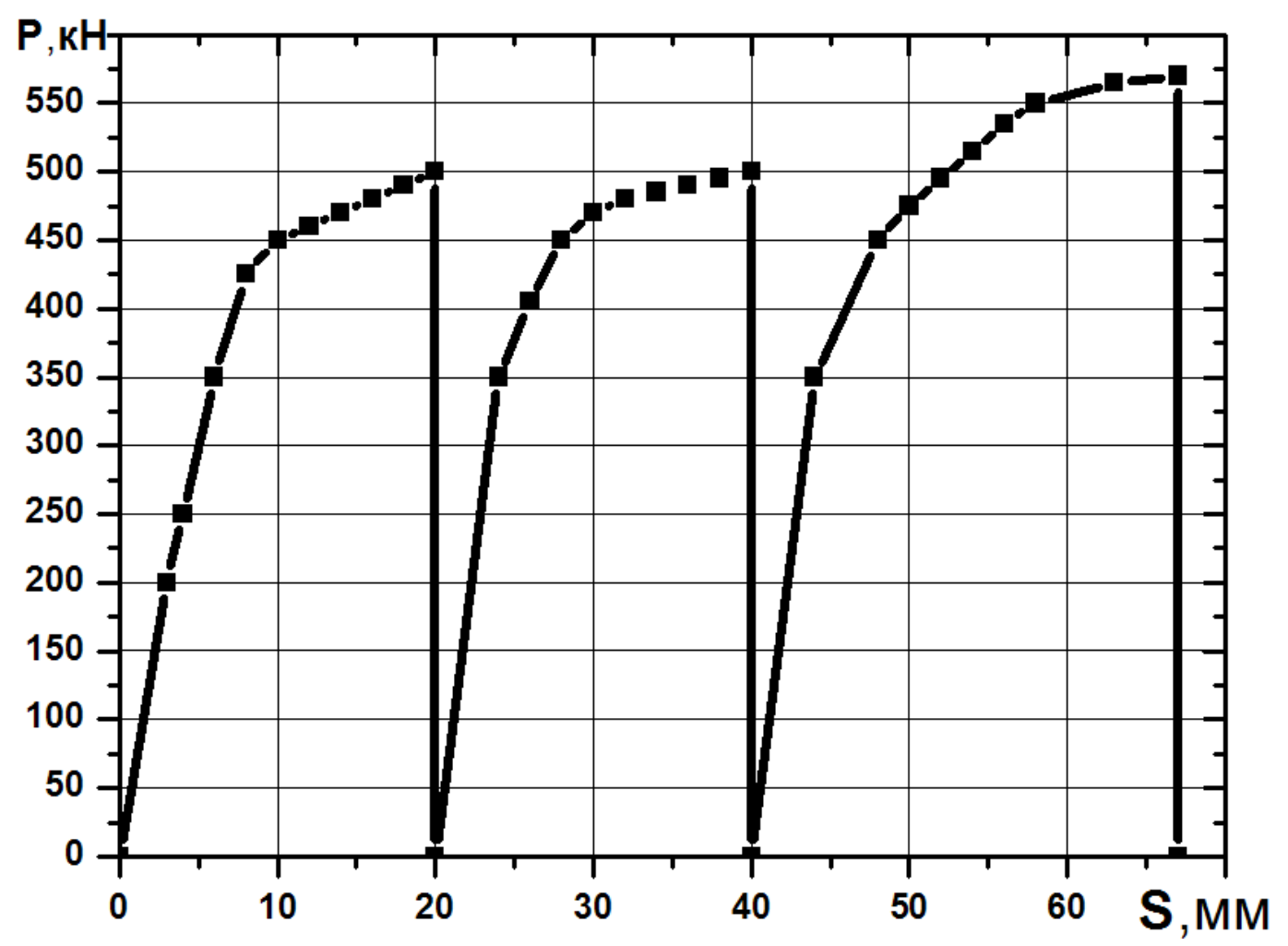

Рис. 3. Графік залежності сили видавлювання $P$ від ходу робочого пуансона $S$

\section{ВИСНОВКИ}

Розрахунки в QForm 2D/3D підтвердили можливість виготовлення складнонопрофільованої порожнистої деталі зворотно-радіальним видавлюванням в умовах реального виробництва за рахунок додаткової кінематики переміщення матриці на відповідних етапах видавлювання.

Осередок деформації зосереджений під пуансоном на певну глибину і в стінці одержуваного стакану.

Максимальне значення інтенсивності деформацій спостерігаються у зоні перехідної кромки пуансона (в області калібруючого пояска пуансона) і досягають значення $\varepsilon_{\mathrm{i}}=6,5$. Розташування максимальних значень інтенсивності напружень майже збігаються 3 розміщенням осередку деформації в деформованому об'ємі і досягають значення $\sigma_{i}=190$ МПа.

Було встановлено, що з переміщенням активного пуансону постійно збільшується сила деформування від нуля до 500 кН в кожній з трьох зон видавлювання через те, що постійно збільшується об’єм осередку деформації в заготовці, яка деформується.

\section{СПИСОК ВИКОРИСТАНОЇ ЛІТЕРАТУРИ}

1. Алиев И. С. Технологические возможности новых способов комбинированного выдавливания. Кузнечно-итамповочное производство. 1990. 2. С. 7-10.

2. Алиева Л. И. Процессы комбинированного деформирования и выдавливания. Обработка материалов давлением. 2016. 1 (42). 100-108.

3. Алиева Л. И. Совершенствование процессов комбинированного выдавливания: монография. Краматорск: ООО «Тираж-51». 2018. 352 с. ISBN 978-966-379-846-2.

4. Калюжний В. Л., Цибенко А. С., Чувільов Ю. О., Чувільов Є. О. Використання холодного штампування для отримання порожнистого виробу з необхідними властивостями здеформованого металу. Вісник НТУУ «КПI». Серія машинобудування. 2015. 1(73). С. 124-130.

5. Aliiev I., Aliieva L., Abhari P., Goncharuk K. Investigation of defect in combined precision extrusion process with multiple ram. Proceedings of the 16th International conference "New technologies and achievements in metallurgy, material engineering and production engineering”. Series : Monographs. Czestochowa. 2015, 48, pp. 90-93. 
6. Алиева Л. И. Оценка деформированного состояния деталей в процессе холодного выдавливания. Металлургическая и горнорудная промышленность. 2016. 2. С. 77-85.

7. Abhari P. Investigation of fracture moment in radial extrusion process by finite element method. Proceedings of the 18th International scientific conference New technologies and achievements in metallurgy, material engineering, production engineering and physics. Series: Monographs. Częstochowa. 2017, 68, pp. 97-101.

8. Abhari P. Numerical simulation of cold forging process to investigate folding defect in enclosed dies. International Journal of Mechanics and Advanced Technologies. 2017, 2 (80), pp. 71-77. DOI: http ://dx.doi.org/10.20535/2521-1943.2017.79.96079

9. Hrudkina N., Aliieva L., Abhari P., Kuznetsov M., Shevtsov S. Derivation of engineering formulas in order to calculate energy-power parameters and a shape change in a semi-finished product in the process of combined extrusion. Eastern-European Journal of Enterprise Technologies. 2019. Vol. 2, 7 (98), pp. 49-57. DOI: https://doi.org/10.15587/1729-4061.2019.160585

\section{REFERENCES}

1. Aliiev I.S. Technological capabilities of new methods of combined extrusion. Forging and Stamping Production. 1990, 2, pp. 7-10. (in Russian).

2. Aliieva L.I. Processes of combined plastic deformation and extrusion. Material Working by Pressure. 2016, 1(42), pp. 100-108. (in Russian).

3. Aliieva L.I. Improving the processes of combined extrusion: monograph. Kramatorsk: Ltd "Tiraj - 51". 2018, 352 p. ISBN 978-966-379-846-2. (in Russian).

4. Kalyuzhnyi V.L., Tsybenko A.S., Chuvilev Y.A., Chuvilev E.A. The use of cold stamping to obtain a hollow product with the necessary properties of deformed metal. Bulletin of NTUU "KPI". Series of mechanical engineering. 2015, 1 (73), pp 124-130. (in Ukrainian)

5. Aliiev I., Aliieva L., Abhari P., Goncharuk K. Investigation of defect in combined precision extrusion process with multiple ram. Proceedings of the 16th International conference "New technologies and achievements in metallurgy, material engineering and production engineering”. Series: Monographs. Czestochowa. 2015, 48, pp. 90-93.

6. Aliieva L.I. Assessment of the deformed state of parts during cold extrusion. Metallurgical and mining industry. 2016, 2. pp. 77-85. (in Russian).

7. Abhari P. Investigation of fracture moment in radial extrusion process by finite element method. Proceedings of the 18th International scientific conference New technologies and achievements in metallurgy, material engineering, production engineering and physics. Series: Monographs. Częstochowa. 2017, 68, pp. 97-101.

8. Abhari P. Numerical simulation of cold forging process to investigate folding defect in enclosed dies. International Journal of Mechanics and Advanced Technologies. 2017, 2 (80), pp. 71-77. DOI: http ://dx.doi.org/10.20535/2521-1943.2017.79.96079

9. Hrudkina N., Aliieva L., Abhari P., Kuznetsov M., Shevtsov S. Derivation of engineering formulas in order to calculate energy-power parameters and a shape change in a semi-finished product in the process of combined extrusion. Eastern European Journal of Enterprise Technologies. 2019. 2,7 (98), pp. 49-57. DOI: https://doi.org/10.15587/1729-4061.2019.160585

Абхарі П. Б. - д-р техн. наук, доц. каф ОМТ ДДМА;

E-mail: omd@dgma.donetsk.ua;

Малій Х. В. - канд. техн. наук, ст. викл. каф. ОМТ ДДМА;

Кузенко О. А. - аспірант кафедри ОМТ ДДМА.

ДДМА - Донбаська державна машинобудівна академія, м. Краматорськ. 